\title{
Smoking, Epidemiology and E-Cigarettes
}

"The true face of smoking is disease, death and horror - not the glamour and sophistication the pushers in the tobacco industry try to

portray." - David Byrne

In our fellows' conference we recently reviewed the evolution of the science of clinical epidemiology as it relates to the association of smoking and lung cancer and the concurrent history of tobacco marketing in the United States.

This story begins in 1950, when Richard Doll and Austin Bradford Hill published their landmark case control study demonstrating the association between smoking and lung cancer (1). This study was performed with methodological standards that have rarely been matched in the 63 years since. Exhaustive analysis of possible confounders, a multi-stage evaluation of study blinding, determination of dose-effect, and the use of multiple analyses to establish consistency are among many examples of superb attention to detail exercised by Doll and Hill in this study. The results showed that patients with lung cancer were about 15 times more likely than matched control patients to have smoked tobacco (Odds ratio 15). The $p$-value was 0.00000064 - indicating that the probability of calculating such a result by chance alone is less than one-in-a-million. In comparison, many modern case control trials are characterized by weak associations (odds ratios of 1-3) with p-values that are barely significant. Yet the phenomenal and nearly unparalleled results of this study had practically no discernable effect on the increasing rate of smoking in the following decade.

Many factors opposed the conclusions of Doll and Hill. Atmospheric pollution - perhaps emanating from motor car exhaust or asphalt tarmac - was felt to be the leading suspect in the increasing incidence of lung cancer. At the time, it seemed inconceivable to most people that smoking could cause cancer. Two thirds of British men smoked. Smoking was widely endorsed by the medical profession - Doll and Hill themselves had both previously been smokers. The British Department of Health did not endorse their findings, amid worries that the study might start a panic. Several prominent statisticians, including Sir Ronald Fisher, publicly criticized their study design and conclusions. Fisher was a polymath - a genius with significant accomplishments in multiple disciplines, widely recognized as the founder of modern statistics, having invented Fisher's exact test, and ANOVA and having collaborated in the development of the Student's T 
test. Fisher was also an avid smoker. It was later disclosed that Fisher had lucrative financial ties to the tobacco industry, raising questions whether Fisher's criticisms of Doll and Hill were bought and paid for.

Doll and Hill followed up with a stronger study design - performing one of the finest cohort studies ever - the British Physician's study. They enrolled over 40,000 British Physicians - almost $70 \%$ of all registered in Britain. Outcomes in this cohort were eventually evaluated over 50 years, and contributed to our knowledge in many areas of medicine. But the results in regards to the relationship between smoking and lung cancer were objectively convincing within the first decade of follow-up. In an interim analysis in 1961 (2), the relative risk for lung cancer in smokers was found to be increased 18 times - consistent with the findings of their case control trial. Fisher's exact test was incalculable in 1961 since it required the quantization of enormous factorials, but I calculated a p-value of 0.0000000000000001 (one in 100-quadrillion) using their data and an on-line Microsoft statistics program. It's satisfying to find that Fisher's namesake statistic so convincingly validates the conclusions that he personally refuted. Sir Austin Bradford Hill is famous for his contention that we often overfocus on achieving a $\mathrm{p}$-value $<0.05$ in modern medical research - the incomparable statistical significance of this study illustrates his point.

Despite increasing scientific evidence against smoking, cigarette consumption in the U.S. continued to rise, and did not fall below pre1950 levels until the early eighties. A further generation of young men took on the habit, many of which were introduced to smoking in the armed services - cigarettes having been routinely included in C-rations of US soldiers who fought in WWII, Korea and Viet Nam. Cigarette smoking was endorsed by everyone from movie stars, to sports stars to doctors - Bob Hope, Mickey Mantle and Ronald Reagan among them. Santa Claus appeared in multiple ads with a cigarette in one hand, and his red toy bag in the other - fecklessly endorsing multiple different brands including Lucky Strikes and Pall Malls.

Several tobacco advertisement campaigns were particularly influential. Philip Morris introduced the "Marlboro Man", considered one of the most brilliant ad campaigns in history, in 1954. Marlboro cigarettes were filtered. The implied (but factitious) protective benefits of the filter were not explicitly marketed, but filtered cigarettes were considered "feminine" at the time. The use of real rodeo cowboys in the Marlboro ads dramatically changed that impression - particularly in the minds of post adolescent boys. One indication of the success of 
the Marlboro Man is that Philip Morris is said to have spent $\$ 300$ million dollars finding a replacement when Darrell Winfield, the most famous of the Marlboro men, retired.

In the late sixties, Philip Morris also marketed smoking to young women with a brand designed specifically for women called Virginia Slims. Riding the wave of women's liberation, the slogan "You've come a long way baby" promoted smoking as a way to express emancipation and empowerment. RJ Reynolds introduced the "Joe Camel" ad campaign in 1987, allegedly targeting children with a coollooking cartoon of an anthropomorphic camel. Sounds silly, I know, but it worked. In 5 short years after starting this campaign, the annual sales of Camel cigarettes to teenagers rose from 6 million to 470 million dollars. At its peak, it was shown that six-year-old children could associate the character of "Joe Camel" with Camel cigarettes about as frequently as they could associate Mickey Mouse with Disney. A study published in JAMA concluded that tobacco experimentation by 700,000 adolescents per year could be attributed to targeted advertising (3).

Although public education had already made great inroads in reducing smoking in the US by the 80 's, legal and governmental anti-smoking pressure began to build thereafter. In 1988, Rose Cipollone posthumously won the first successful wrongful harm lawsuit of a smoker against a tobacco manufacturer. Mangini sued RJ Reynolds on behalf of children in regards to the Joe Camel ad campaign. In the 1988 Report of the Surgeon General, C Everett Koop concluded that nicotine has an addictiveness similar to that of heroin. C Everett Koop's continuing efforts to raise public awareness initiated some of the first public discourse in regards to the dangers of second-hand smoke (subsequently found to cause 50,000 deaths per year in the U.S.). Smoking rates in the United States declined from $38 \%$ to $27 \%$ during his tenure.

In the 1990s, the tobacco lobby engaged in a comprehensive and aggressive political effort to neutralize clean indoor air legislation, minimize tobacco tax increases, and preserve the industry's marketing strategies. However the famous Waxman congressional hearings intervened in 1997. In sworn testimony before congress, the CEOs of seven major tobacco companies famously asserted that smoking tobacco was not addictive, contrary to incontrovertible scientific evidence. Two sources revealed their insincerity. The first was testimony of previous employees of the tobacco industry, such as 
Jeffrey Wigman and Victor DeNoble, who testified that the addictive and carcinogenic properties of cigarette tobacco had been artificially manipulated by the industry. The second was the discovery of internal tobacco industry memos, which revealed that the addictive properties of tobacco were well recognized within the industry as early as 1960s. A few excerpts follow:

"... nicotine is addictive. We are, then, in the business of selling nicotine, an addictive drug" July 17, 1963 report by then Brown \& Williamson general counsel/vice president Addison Yeaman.

"The cigarette should be conceived not as a product but as a package. The product is nicotine. ... Think of a cigarette as a dispenser for a dose unit of nicotine..." 1972 William Dunn, Jr., of the Philip Morris Research Center, "Motives and Incentives in Cigarette Smoking."

"Within 10 seconds of starting to smoke, nicotine is available in the brain. . . giving an instantaneous catch or hit . . Other "drugs" such as marijuana, amphetamines, and alcohol are slower" Circa 1980 C.C. Greig in a BAT R\&D memo

The Waxman hearings resulted in a $\$ 368$ billion dollar assessment against the tobacco industry, and increased restrictions on advertising and lobbying. Shortly thereafter, the Joe Camel and Marlboro Man ad campaigns were terminated. With the public revelation that three previous Marlboro Men had died from lung cancer, that ad campaign had lost its appeal.

In the late 90 s/early 2000 s, the nicotine content of all major brands of cigarettes was progressively increased on average by $1.8 \%$ per year. This might theoretically make it harder for smokers to kick the habit. Sales promotions totaling about $\$ 400$ per year per smoker were directed at loyal smokers. Despite restrictions, the tobacco industry continued to invest $\$ 25$ million dollars per year in lobbying. Upon further negotiation, the tobacco master settlement was reduced to 200 billion - only 12.7 billion to be paid up front. The full details of this settlement have become increasingly legally obfuscated over time in my opinion; some states are actually selling tobacco settlement bonds now to protect themselves against loss of future return from the settlement.

Although US cigarette consumption has dramatically fallen, worldwide sales are peaking, and the international rates of women smokers are still on the rise. Philips Morris restructured and rebranded their corporation as Altria (sounds like the word "altruistic"). They 
subsumed Kraft and Nabisco foods, but the majority of their $>100,000$ million dollars in annual revenue are derived from tobacco sales, about two-thirds of which are international.

Many US tobacco firms are rapidly investing in production and marketing of electronic cigarettes that vaporize nicotine for inhalation. It is likely that inhaling vaporized nicotine is less dangerous than smoking tobacco. However, the health effects of inhaling vaporized nicotine are not well studied yet. The purported benefits of vaping over smoking have already been publicly aired as an argument to turn back current restrictions on public smoking. Electronic cigarettes are being advertised as glamorous again in advertisements reminiscent of tobacco ads seen in the 1970s. E-cigs in which nicotine is flavored with chocolate, or various fruit flavors, seem to once-again target children. The promotion of a highly addictive drug to children and young adults cannot be beneficial to society in the long term, even if vaping doesn't lead to lung cancer. But the rapid increase in vaping promises that another round in the societal struggle against nicotine addiction is about to begin again.

Doll and Hill's work played a tremendous beneficial role in this story. Their case control and cohort studies set the methodological standard by which all subsequent observational trials should be measured although our experience in journal club is that modern observational trials don't even come close. Furthermore, their work became the basis for the subsequent formulation of the "Bradford Hill Criteria" for establishing causation, which still plays a dominant role in medical and medicolegal reasoning.

Robert A. Raschke, MD Associate Editor

\section{References}

1. Doll $R$, Hill $A B$. Smoking and carcinoma of the lung; preliminary report. Br Med J. 1950;2(4682):739-48. [CrossRef]

2. Doll $R$, Hill $A B$. The mortality of doctors in relation to their smoking habits; a preliminary report. Br Med J. 1954;1(4877):1451-5. [CrossRef]

3. Pierce JP, Choi WS, Gilpin EA, Farkas AJ, Berry CC. Tobacco industry promotion of cigarettes and adolescent smoking. JAMA. 1998;279(7):511-5. [CrossRef] [PubMed] 